\title{
A COMPARATIVE STUDY OF INTRAPULMONARY GAS MIXING AND FUNCTIONAL RESIDUAL CAPACITY IN PULMONARY EMPHYSEMA, USING HELIUM AND NITROGEN AS THE TEST GASES ${ }^{1,2}$
}

\author{
By JOHN B. HICKAM AND REGINA FRAYSER
}

(From the Department of Medicine, Duke University School of Medicine, Durham, N. C.)

(Submitted for publication October 21, 1957; accepted November 14, 1957)

In describing the open circuit nitrogen method for estimating residual lung capacity, Darling, Cournand, and Richards (1) pointed out that imperfect gas mixing in the lung could impair the accuracy of the method. More recent studies have demonstrated that intrapulmonary gas mixing can be markedly uneven in patients with pulmonary emphysema (2-7). The mixing defect in advanced emphysema is often severe enough to make it likely that the functional residual capacity could be underestimated significantly by the Darling method, using the customary seven minute washout period.

In this laboratory an open-circuit helium method has been used which was designed to be particularly suited to the measurement of functional residual capacity in persons with defective intrapulmonary gas mixing (6). The method also provides a measure of intrapulmonary gas mixing in the form of an estimate of the size and turnover rate of the most slowly ventilated portion of the lung. In some patients with advanced emphysema and impaired mixing, the method has yielded values for functional residual capacity and total lung volume which are unusually large by conventional standards (7). In order to clarify the extent to which impaired gas mixing can introduce error into the measurement of functional residual capacity by conventional means, a comparative study has been made of the helium and the Darling methods in normal and emphysematous subjects. In order to evaluate the extent to which the measurement of functional residual capacity and intrapulmonary gas mixing by the helium method might be affected by the characteristics of the test

1 This investigation was supported by a research grant, $\mathrm{H}-1370$ (C3), from the National Heart Institute, Public Health Service.

2 This paper was presented at the Forty-seventh Annual Meeting of the American Society for Clinical Investigation, Atlantic City, N. J., May 2, 1955. gas, a study was also made of the effect of substituting nitrogen for helium as the test gas in this procedure. The present report describes the results of these studies. In general, the results confirm the suspicion that the Darling method can significantly underestimate the functional residual capacity in advanced emphysema and indicate that the values obtained by the helium method are not dependent upon special properties of the test gas.

\section{METHODS}

The method which employs helium for measuring the functional residual capacity (FRC) and gas mixing within the slowly ventilated portions of the lung has been described in detail elsewhere (6). The subject first breathes for 15 minutes a mixture of 50 per cent helium and 50 per cent oxygen. Then, at the end of a quiet expiration, he is switched to tank oxygen, and the expired gas is collected over the next seven minutes or more for subsequent measurement of its volume and helium concentration. The helium concentration of expired gas is followed continuously by means of a sensitive katharometer between levels of 3.00 and 0.05 per cent helium. When the concentration of expired helium is plotted against time on semilogarithmic paper, the resultant curve tends to form a straight line in the final part of its course. The appearance of this straight line indicates that those portions of the lung which are still excreting helium are being ventilated at similar enough rates to behave as though they constituted, in the aggregate, a single homogeneously ventilated space, which, for convenience, has been called the "slow space." From the slope and position of the terminal straight line and from the total minute ventilation volume $(\mathrm{Vt})$ of the subject it is possible to calculate values for the volume $(\mathrm{Vs})$ and ventilation rate (Vs) of the slow space. It is also possible to estimate the amount of helium remaining in the lung at any time after the slope and position of the straight-line part of the concentration-time curve has become clearly defined. For measurement of the FRC, the amount of helium contained within the lung at the start of the washout procedure is determined as the sum of that contained in the collecting bag and that estimated by graphic means still to be contained within the lung at the time collection is stopped. Where intra- 
pulmonary gas mixing is very slow, a correction can be made for failure of the slow space to equilibrate completely with the inhaled helium mixture during the preliminary 15 minute period. When this correction is made, it increases the value obtained for the FRC. In the present study the largest value for this correction was $400 \mathrm{ml}$. (Case 7, Table II), and the average value of the correction for Cases 1 to 13 (Table II) was $120 \mathrm{ml}$.

When nitrogen was used as the test gas during the present study, a similar open-circuit arrangement was employed. The initial concentration of nitrogen in the lungs was assumed to be 81 per cent, and tank oxygen was used as the washing gas. The nitrogen concentration of mixed, expired gas was followed continuously by a nitrogen meter ${ }^{3}$ between levels of 5.0 and 0.2 per cent $\mathrm{N}_{2}$. As with the helium analysis, the sampled gas was drawn through an Ascarite train on the way to the nitrogen meter for removal of water vapor and $\mathrm{CO}_{2}$. The volume of this train was adjusted to provide a 25 second delay between sampling point and meter, to correspond to the time lag in the helium analysis. During the nitrogen washout procedure, the meter was read directly at appropriate intervals, or its output was amplified and recorded by a direct writer. Used as described, over this narrow range, the nitrogen meter proved to be quite reliable and stable. Calibration of the instrument was carried out with gas samples prepared by mixing known volumes of nitrogen and tank oxygen in a water displacement apparatus. With the nitrogen meter set as though tank oxygen contained no nitrogen, a linear relationship was found between the calculated nitrogen concentrations of the mixtures and the values as read from the nitrogen meter for the range 0.1 to 5.5 per cent $\mathrm{N}_{2}\left(\mathrm{~N}_{2}\right.$ per cent equals meter reading plus 0.02$)$. Over this range the standard deviation from regression was 0.04 per cent nitrogen. The same standard deviation from regression was found for the measurement of helium concentration by the katharometer in the range 3.00 to 0.05 per cent helium. To correct for the effect of absorbing approximately 2.5 per cent $\mathrm{CO}_{2}$ by the Ascarite ${ }^{\circledR}$ train before analysis of expired gas, the readings of both helium and nitrogen were multiplied by the factor of 0.975 .

For the measurement of FRC by the open-circuit method of Darling, which was carried out as a separate procedure, the expired gas was collected during seven minutes of oxygen breathing for subsequent determination of its volume and nitrogen concentration. Nitrogen concentration of the gas in the bag was measured by the nitrogen meter, using the Ascarite ${ }^{\circledR}$ absorber, as described above. During the washout, the intake valve of the nitrogen meter was connected into the mouthpiece so that the subject's expired air could be directly sampled without delay, drying, or $\mathrm{CO}_{2}$ absorption. This arrangement allowed recording of the highest nitrogen concentration achieved during a prolonged, forced expiration at the end of the seven minute washout period. This value was used as the alveolar nitrogen concentration in calculating the FRC by the Darling method. For this

3 Waters-Conley. analysis the nitrogen meter was "set" with gas mixtures of known nitrogen concentration which were saturated with water vapor rather than dry. It was necessary to use a different calibration line because of the presence of carbon dioxide and water vapor in the alveolar sample. This calibration line was derived from the analysis of 15 alveolar gas samples delivered by normal subjects after short periods of breathing oxygen. As determined on the Scholander apparatus, the nitrogen concentration of these samples ranged between 1.0 and 12.3 per cent and the $\mathrm{CO}_{2}$ was in the vicinity of 5 to 6 per cent. Calculation of the regression line yielded the expression:

$$
\mathrm{N}_{2} \text { per cent equals } \frac{\text { meter reading plus } 0.24}{0.96} \text {, }
$$

with a standard deviation from regression of 0.19 per cent. To estimate the sensitivity of this calibration to changes in $\mathrm{CO}_{2}$ concentration, a regression line was also calculated for a series of samples made by adding nitrogen to a gas mixture of approximately 10 per cent $\mathrm{CO}_{2}, 90$ per cent $\mathrm{O}_{2}$, with a subsequent Scholander analysis (8). For nitrogen concentrations between 2.0 and 17.0, the result was:

$$
\mathrm{N}_{2} \text { per cent equals } \frac{\text { meter reading plus } 0.65}{0.96} \text {, }
$$

with a standard deviation of 0.12 per cent. It is apparent that use of the calibration curve obtained with normal subjects might slightly underestimate the alveolar nitrogen concentration of a subject with hypercapnia, but the error introduced into the Darling method would not be great.

From the data of Behnke and Willmon (9), and of Jones (10), corrections were made for the amount of helium and nitrogen contributed by the body tissues during the washout period. This was done by constructing curves for the rate of elimination of test gases from the body tissues as a function of the duration of washout, taking into account the short equilibration period with helium. This correction is necessarily crude. To indicate the magnitude of the correction, the cumulative tissue contribution after 7,15 , and 30 minutes of washout was estimated to be, respectively, for nitrogen 220,320 , and $430 \mathrm{ml}$., and for helium 40,60 , and $80 \mathrm{ml}$. The usual corrections were made for apparatus dead space.

Calculations have been described elsewhere (6).

Observations were made on 21 male patients with obstructive pulmonary emphysema. The diagnosis was based on clinical and roentgenologic findings. In most cases, but not in all, the disease was far advanced. In 13 of the patients the FRC was measured both by the Darling method, using nitrogen, and by the prolonged washout method, using both helium and nitrogen. For the most part these measurements were all made at a single session, but in a few cases two sessions were needed. Rest periods of not less than 30 minutes were interposed between determinations by the different methods. The usual order of procedure was: seven minute 
nitrogen, prolonged nitrogen washout, and prolonged helium washout. All measurements were made with the subjects in a sitting position. In 11 normal male volunteers, the FRC was measured both by the Darling method and the helium washout method.

\section{RESULTS}

The results obtained with the normal subjects are summarized in Table I. The mean lung volumes are similar to those reported elsewhere for normal subjects (11). In particular, there is good agreement between the FRC values measured by the Darling method and those measured by the helium washout method.

Table II summarizes the data obtained from the patients with emphysema. In general, these subjects had advanced emphysema as suggested by the large ratios of residual lung volume to total capacity. There is good agreement between the mean FRC measurements by the helium and the nitrogen washout methods. However, the mean FRC by the seven minute washout and alveolar $\mathrm{N}_{2}$ method (Darling) was 0.53 liters less than the mean value yielded by the helium washout method. The difference is significant $(\mathrm{p}<0.01)$. In five cases the volume by the helium method was more than 0.8 liters greater than that by the Darling method. Figure 1 relates the difference between these two measurements to the severity of the emphysema as indicated by the ratio of residual lung volume to total lung capacity (helium estimate). There appears to be a general tendency for the difference to increase as the severity of the emphysema increases.

There was no consistent difference between the size and ventilation rate of the slow spaces in emphysematous subjects as measured by helium washout on the one hand, and nitrogen washout on the other. Since the speeds of diffusion of gases are inversely proportional to the square roots of their densities (Graham's law), helium would be expected to "wash out" of a slow space more rapidly than nitrogen if the rate of gas diffusion were a limiting factor in the ventilation of such spaces. The expectation that helium and nitrogen would give different results for slow space characteristics under certain circumstances was investigated with a model lung and slow space. As shown in Figure 2, the "lung" consisted of a box which was ventilated by gas entering in a

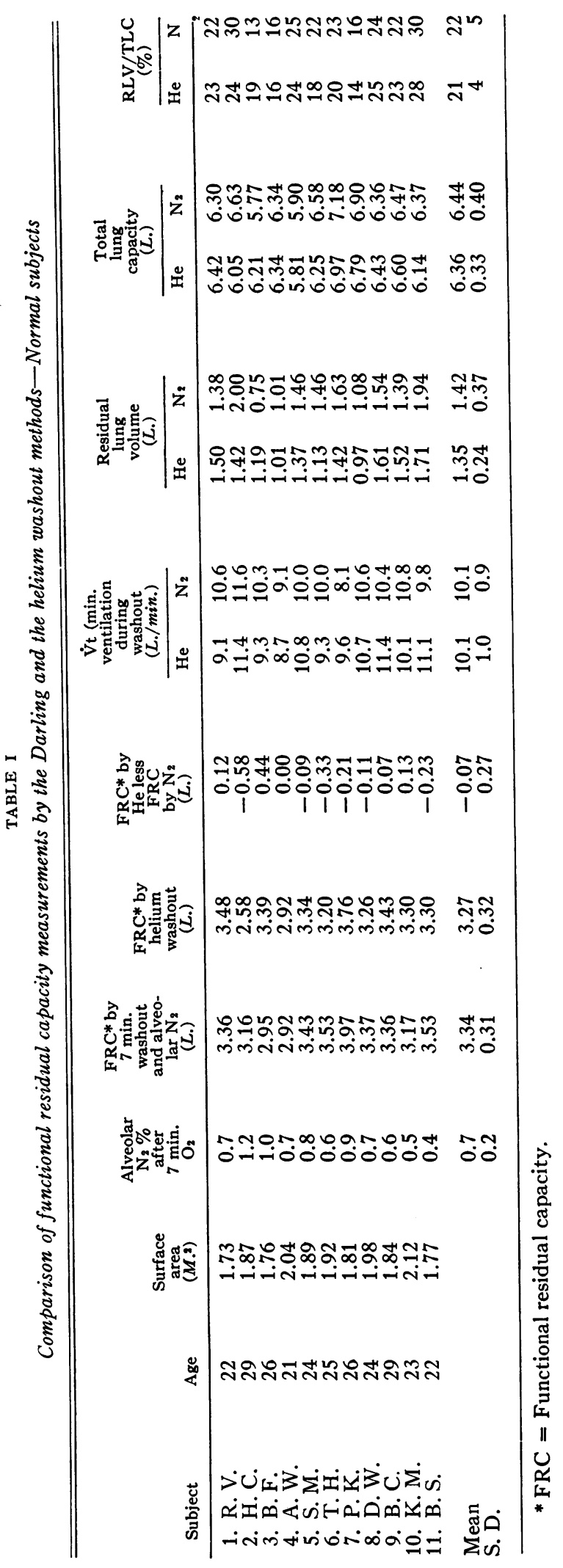




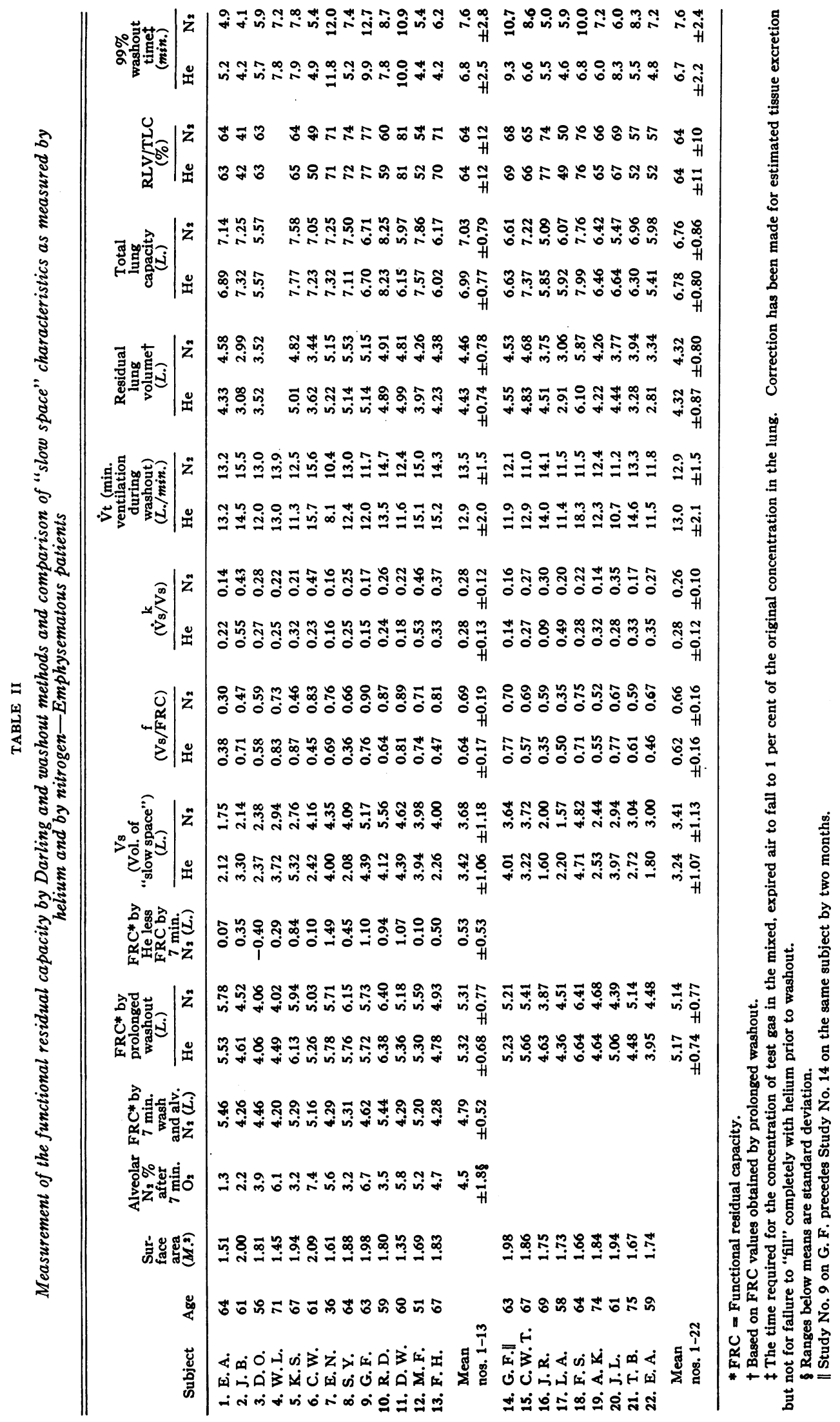




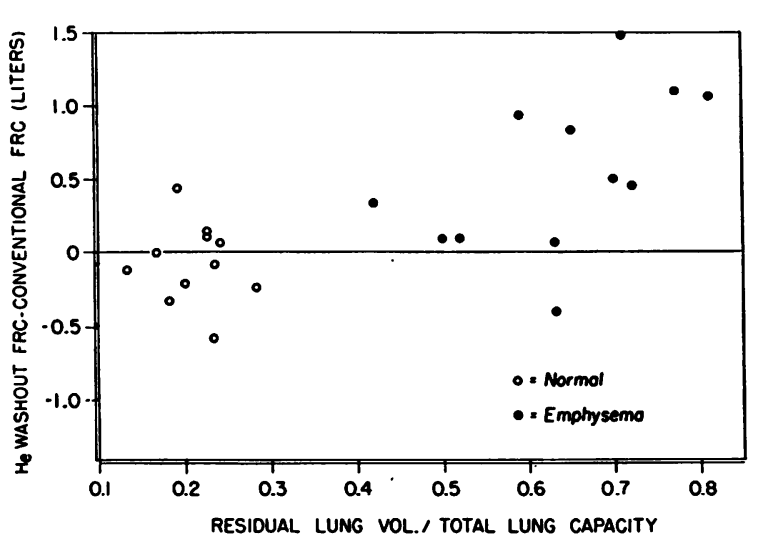

Fig. 1. Difference Between Helium Washout and Conventional Open-Circuit functional Residual Capacity Measurements in Normal and EMPHYSEMATOUS SUBJECTS

In the normal subjects there is good overall agreement between the two methods, but in the subjects with emphysema the results by the helium method are, as a group, significantly greater than those by the method of Darling, Cournand, and Richards.

steady flow through holes in corner pipes and leaving by a central exhaust pipe. The two different "slow spaces". consisted of hollow inserts placed within the lung. The "convection" insert communicated with the surrounding lung by numerous holes $1 \mathrm{~mm}$. in diameter. Ventilation of the surrounding lung produced slow convection currents in the insert, made visible by filling it with smoke. The "diffusion" insert was a cylinder closed at the ends by two Grade IV sintered bronze "porex" discs described by the manufacturer ${ }^{4}$ as having pores with a general size range of 0.0001 to 0.0005 inch in diameter. Ventilation of the surrounding lung produced no visible convection currents in the insert. Ventilation of

4 Moraine Products Division, General Motors Corporation.

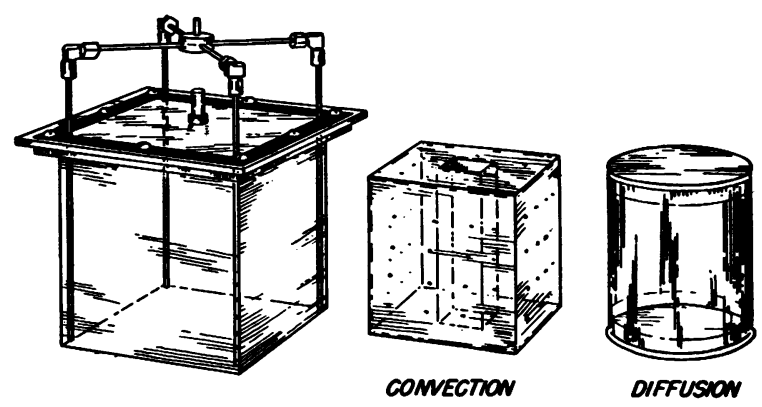

Fig. 2. Model Lung with "Slow Space" Inserts For description, see text.

this insert must have involved to some extent the process of gas diffusion through the pores. Using nonventilated dummy inserts, flow through the lung was first adjusted to provide substantially uniform ventilation in the space around the insert as judged by the washout curves. Oxygen was used as the washing gas. For helium washouts, the lung and insert were filled at the start with 50 per cent helium and 50 per cent oxygen, and for nitrogen washouts they were filled with air. The results obtained with the two different inserts and the two different test gases are presented in Table III. The slow space caused by the "convection" insert had substantially the same size and turnover rate when measured by helium as when measured by nitrogen. However, with the slow space caused by the "diffusion" insert, the turnover rate by helium was considerably faster than by nitrogen. This result confirmed the expectation that the two different test gases might give different slow space characteristics in cases where the process of diffusion was a limiting factor in slow space ventilation.

\section{DISCUSSION}

The essential difference between the helium washout and Darling methods for measuring

TABLE III

Influence of the nature of the test gas on apparent characteristics of the slow space in a model lung

\begin{tabular}{|c|c|c|c|c|c|c|c|}
\hline $\begin{array}{c}\text { Slow space } \\
\text { insert }\end{array}$ & Test gas & $\begin{array}{l}\mathrm{Vt} \\
\text { Volume } \\
\text { of lung } \\
\text { and insert } \\
(m l .)\end{array}$ & $\begin{array}{c}\text { Volume } \\
\text { of insert } \\
(\mathrm{ml} .)\end{array}$ & $\begin{array}{c}\dot{\mathrm{v} t} \\
\text { Total } \\
\text { ventilation } \\
\text { rate } \\
(\text { ml. } / \text { min. })\end{array}$ & $\begin{array}{c}\text { Vs } \\
\text { Calculated } \\
\text { slow space } \\
\text { volume } \\
(m l .)\end{array}$ & $(\dot{\mathrm{V}} \mathbf{s} / \mathrm{ks})$ & $\left(\mathrm{Vs}_{\mathrm{s}} / \mathrm{fRC}\right)$ \\
\hline "Convection" & $\begin{array}{l}\text { Helium } \\
\text { Nitrogen }\end{array}$ & $\begin{array}{l}1,980 \\
1,980\end{array}$ & $\begin{array}{l}910 \\
910\end{array}$ & $\begin{array}{l}2,400 \\
2,400\end{array}$ & $\begin{array}{l}830 \\
920\end{array}$ & $\begin{array}{l}0.26 \\
0.22\end{array}$ & $\begin{array}{l}0.42 \\
0.46\end{array}$ \\
\hline "Diffusion" & $\begin{array}{l}\text { Helium } \\
\text { Nitrogen }\end{array}$ & $\begin{array}{l}2,080 \\
2,080\end{array}$ & $\begin{array}{l}830 \\
830\end{array}$ & $\begin{array}{l}2,400 \\
2,400\end{array}$ & $\begin{array}{l}1,090 \\
1,280\end{array}$ & $\begin{array}{l}0.77 \\
0.46\end{array}$ & $\begin{array}{l}0.52 \\
0.61\end{array}$ \\
\hline
\end{tabular}


functional residual capacity lies in the means used to estimate the amount of test gas remaining within the lung after the first few minutes of washout. In the helium method the expired air is continuously monitored by a sensitive analytical system to insure that measurement of the excreted test gas continues until the excretion rate becomes negligible. In the Darling method the mean concentration of test gas remaining in the lung after seven minutes of washing is estimated from the composition of an alveolar air sample. The present results indicate that in patients with the severe mixing defect of advanced emphysema, the alveolar air method significantly underestimates the amount of test gas remaining within the lung and consequently underestimates the functional residual capacity, sometimes by a considerable quantity. It is apparent from these and from previous results $(6,7)$ that the poorly ventilated lung. regions in such patients usually make a relatively small contribution to alveolar air samples. The contribution is often large enough in patients with advanced emphysema to yield an abnormally high nitrogen concentration in the seven minute alveolar sample of the Darling method, as found by Cournand, Baldwin, Darling, and Richards (12). There is, however, no consistent relationship in the present patients between the height of the seven minute alveolar nitrogen concentration and the severity of the mixing defect, as judged by the amount of nitrogen remaining in the lungs in excess of that estimated from the alveolar sample (Table II).

Using a plethysmographic method for the measurement of thoracic gas volume, Bedell, Marshall, DuBois, and Comroe (13) have found values in patients with emphysema sometimes considerably in excess of the functional residual capacity yielded by the Darling method, while the agreement was quite good in patients with some other pulmonary disorders and in normal subjects. Since this method can measure noncommunicating gas volumes, such as closed cysts, it would also be expected to give results larger than those by the helium method in some cases of emphysema. These results and others indicate that the functional residual capacity and total lung volume in severe emphysema are generally larger than previously thought.

The finding that nitrogen can be substituted for helium in the washout method without producing a significant difference in the functional residual capacity or a consistent change in the characteristics of the "slow space" in emphysematous patients indicates that the results with this method are not dependent upon special characteristics of the test gas. It also indicates that the process of diffusion is not in general a limiting factor in slow space ventilation.

The results with the model draw attention to the fact that the apparent characteristics of a slow space depend in part upon the mechanics of its ventilation. It was pointed out by Robertson, Siri, and Jones (2) that if a slow space is ventilated in parallel with the rest of the lung, its size and turnover rate can be well estimated by following the rate at which it excretes a test gas, as in the present method. However, if it is ventilated in series, in the sense that it exchanges gas with a faster ventilated space which in turn exchanges with the outside, it is imperfectly characterized by the present method. Series ventilation makes a slow space appear bigger and slower than it actually is, but the apparent size is affected more than the turnover rate. The distortion is small when the slow space is ventilated much more slowly than the fast space with which it is exchanging, but as the turnover rates become similar, distortion becomes large. This effect may account in part for the tendency of the method to overestimate the size of the diffusion insert, which has a relatively fast turnover rate (Table III). Series ventilation must certainly occur to some extent in both normal and diseased lungs. In the usual patient with emphysema, the representation of the slow space is probably fairly accurate because of the great difference between its ventilation rate and that of the rest of the lung. In normal subjects, however, slow spaces are much more rapidly ventilated and consequently they will be somewhat overemphasized by the occurrence of series ventilation.

\section{SUM MARY}

1. A comparative study has been made of the measurement of functional residual capacity by the method of Darling, Cournand, and Richards and by the open circuit helium washout method in normal subjects and in patients with pulmo- 
nary emphysema. In the normal subjects, agreement between the two methods was good, but in the patients with emphysema a significantly larger mean value was obtained by the helium method than by the Darling method. This discrepancy appears to result from the inability of an alveolar air sample to represent adequately the mean intrapulmonary gas concentration in patients with severe defects in intrapulmonary gas mixing.

2. Substitution of nitrogen for helium in the washout procedure made no significant difference in the measurement of functional residual capacity and produced no consistent changes in the apparent characteristics of the slowly ventilated lung spaces of patients with emphysema.

3. The rate of gas diffusion is apparently not a limiting factor in the ventilation of the large, slowly ventilated lung regions of patients with pulmonary emphysema.

\section{REFERENCES}

1. Darling, R. C., Cournand, A., and Richards, D. W., $\mathrm{Jr}$. Studies on the intrapulmonary mixture of gases. III. An open circuit method for measuring residual air. J. clin. Invest. 1940, 19, 609.

2. Robertson, J. S., Siri, W. E., and Jones, H. B. Lung ventilation patterns determined by analysis of nitrogen elimination rates; use of the mass spectrometer as a continuous gas analyzer. J. clin. Invest. 1950, 29, 577.

3. Fowler, W. S., Cornish, E. R., Jr., and Kety, S. S. Measurement of alveolar ventilatory components. Amer. J. med. Sci. 1950, n.s. 220, 112.
4. Fowler, W. S., Cornish, E. R., Jr., and Kety, S. S. Lung function studies. VIII. Analysis of alveolar ventilation by pulmonary $\mathrm{N}_{2}$ clearance curves. J. clin. Invest. 1952, 31, 40.

5. Briscoe, W. A. Further studies on the intrapulmonary mixing of helium in normal and emphysematous subjects. Clin. Sci. 1952, 11, 45.

6. Hickam, J. B., Blair, E., and Frayser, R. An opencircuit helium method for measuring functional residual capacity and defective intrapulmonary gas mixing. J. clin. Invest. 1954, 33, 1277.

7. Blair, E., and Hickam, J. B. Quantitative study of intrapulmonary gas mixing in emphysema. Amer. J. Med. 1955, 18, 519.

8. Scholander, P. F. Analyzer for accurate estimation of respiratory gases in one-half cubic centimeter samples. J. biol. Chem. 1947, 167, 235.

9. Behnke, A. R., and Willmon, T. L. Gaseous nitrogen and helium elimination from the body during rest and exercise. Amer. J. Physiol. 1941, 131, 619.

10. Jones, H. B. Respiratory system: Nitrogen elimination in Medical Physics, O. Glasser, Ed. Chicago, Year Book Publishers, Inc., 1950, vol. 2, p. 855.

11. Fowler, W. S. Specific tests of pulmonary function. A. Lung volumes in Methods in Medical Research, J. H. Comroe, Jr., Ed. Chicago, Year Book Publishers, Inc., 1950, vol. 2, p. 181.

12. Cournand, A., Baldwin, E. DeF., Darling, R. C., and Richards, D. W., Jr. Studies on the intrapulmonary mixture of gases. IV. The significance of the pulmonary emptying rate and a simplified open circuit measurement of residual air. J. clin. Invest. 1941, 20, 681.

13. Bedell, G. N., Marshall, R., DuBois, A. B., and Comroe, J. H., Jr. Plethysmographic determination of the volume of gas trapped in the lungs. J. clin. Invest. 1956, 35, 664. 